\title{
Pengaruh Latihan Imagery dan Konsentrasi terhadap Ketepatan Tusukan dalam Olahraga Anggar
}

Mohamad Wahyu Bagus Prakosa $^{a *}$, Agus Hariyanto ${ }^{\mathrm{b}}$, Rini Ismalasari ${ }^{\mathrm{c}}$

${ }^{a}$ Universitas Negeri Surabaya, Indonesia

Correspondence: mohamadprakosa16070805033@mhs.unesa.ac.id

Received: 11 Des 2020 Accepted: 05 Jan 2021 Published: 30 Apr 2021

\begin{abstract}
The purpose of this study is to analyze the effect of imagery and concentration training on puncture accuracy in fencing. It was a quasi-experimental research with a pretest-posttest control group design, involving 15 members of fencing extracurricular club in SMA Muhammadiyah 3 Surabaya. Respondents were then divided into three groups which consisted of 5 people each, which were control group (C), imagery-training group (IM), and concentration-training group (CT). Respondents in IM and CT were assigned to respected training that was conducted for six weeks, and puncture accuracy was measured using kuhadja or fencing skill test before and after 6 -weeks of training. The puncture accuracy score was then statistically analyzed using paired t-test and one-way Anova at confidence level set as 95\%. Paired t-test analysis found that the mean puncture accuracy score in treatment groups (IM and CT) were higher than the control group, with significance value were 0.013 and 0.000 , respectively. Further analysis using Anova test showed that the type of training significantly gave different effect on the pucture accuracy $(\mathrm{p}<0.05)$. From these results we can conclude that the imagery and concentration training are proven to be effective in improving student's ability to perform accurate and precise punctures in fencing.
\end{abstract}

Keywords: accuracy; concentration training; fencing; imagery training.

\begin{abstract}
Abstrak
Penelitian ini bertujuan untuk mengetahui pengaruh latihan imagery dan konsetrasi terhadap ketepatan tusukan dalam olahraga anggar. Penelitian ini merupakan jenis penelitian eksperimen semu (quasi experiment) dengan pretest-posttest control group design. Responden dalam penelitian merupakan siswa SMA Muhammadiyah 3 Surabaya yang mengikuti ekstrakulikuler anggar sebanyak 15 orang. Responden dibagi menjadi tiga kelompok yang masing-masing berisi 5 orang, yaitu kelompok kontrol (C), kelompok yang diberi latihan imagery (IM), dan kelompok yang diberi latihan konsentrasi (CT). Latihan dilakukan selama enam minggu, dan ketepatan tusukan diukur menggunakan kuhadja atau fencing skill test sebelum dan sesudah perlakuan. Skor ketepatan tusukan kemudian dianalisis secara statistik menggunakan paired t-test dan Anova one-way pada taraf kepercayaan 95\%. Dari hasil analisis ditemukan bahwa rerata skor ketepatan tusukan pada kelompok IM dan CT lebih tinggi dibandingkan kelompok kontrol, dengan nilai signifikansi secara berturut-turut sebesar 0.013 dan 0.000. Dari hasil uji Anova juga diketahui bahwa jenis latihan yang diberikan memberikan pengaruh yang berbeda secara signifikan pada masing-masing kelompok perlakuan $(\mathrm{p}<0.05)$. Dari hasil ini dapat disimpulkan bahwa latihan imagery dan konsentrasi yang diberikan terbukti efektif dalam meningkatkan kemampuan siswa untuk melakukan tusukan dengan tepat dan akurat.
\end{abstract}

Kata kunci: akurasi; anggar; imagery; konsentrasi; ketepatan tusukan. 


\section{Pendahuluan}

Sejak lama anggar dikenal sebagai salah satu cabang olahraga elit, khususnya di negara barat (Rasyono \& Decheline, 2019). Anggar telah dipraktikkan sejak jaman sebelum masehi untuk menangkis dan membela diri, namun penggunaannya sebagai olahraga mulai dikenal oleh masyarakat Eropa pada abad ke 15 (Green, 2016). Saat ini, anggar modern muncul sebagai salah satu olahraga kompetitif yang populer dan diakui dalam Olimpiade, dengan anggota federasi mencapai 150 negara di seluruh dunia (Chen et al., 2017). Di Indonesia, perkembangan olahraga anggar menunjukkan peningkatan yang cukup signifikan dalam beberapa tahun terakhir, dimana saat ini telah banyak berdiri pengurus cabang di beberapa daerah yang rutin menyelenggarakan turnamen setiap tahunnya (Fahrurozi, 2016).

Sebagaimana jenis olahraga bela diri lainnya, di dalam anggar dikenal dua macam aktivitas, yaitu kegiatan bertahan dan menyerang (Rasyono \& Decheline, 2019). Seorang pemain anggar tidak hanya dituntut untuk mampu bertahan dan melindungi diri dari serangan lawan saja (Widowati \& Decheline, 2020), tetapi juga harus mampu meluncurkan serangan-serangan balik dengan cepat (Rasyono \& Decheline, 2019). Namun sekalipun memiliki persamaan, ada hal pokok yang membedakan anggar dengan jenis olahraga bela diri lainnya, yaitu adanya penggunaan senjata khas berupa pedang. Pedang yang digunakan dalam anggar terdiri dari tiga macam, yaitu floret (foil), degen (epee), dan sable (sabre), dimana setiap pedang memiliki karakteristik masing-masing (Kontochristopoulos \& Tsolakis, 2019; Rimasa \& Sartono, 2020). Karena melibatkan penggunaan senjata, maka kemampuan dan kelincahan tangan dalam menangkis, menyerang, atau menusuk lawan merupakan ciri khas dari olahraga ini (Kurniawan, 2010; Yanto, 2013).

Olahraga anggar, gerakan menyerang (lunge) merupakan salah satu gerakan kunci yang harus dikuasai oleh setiap pemain (Sorel, Plantard, Bideau, \& Pontonnier, 2019). Efektivitas serangan dalam permainan anggar ditentukan oleh cara pemain dalam menusuk bidang sasaran dengan tepat dan akurat untuk mendapat poin yang sah (Kamaruddin, 2011). Oleh sebab itu, kemampuan pemain dalam melakukan tusukan kepada bidang sasaran menjadi hal yang penting sebab dapat menentukan kemenangan di pertandingan (Ma'arif, 2015). Faktor mental dan psikologis memegang peranan penting dalam hal ini, dimana mental yang baik akan mempengaruhi performa seorang pemain anggar. Kecerdasan pemain dalam membaca situasi dan arah gerakan dari lawan, di samping kemampuan untuk bisa fokus terhadap bidang sasaran merupakan hal yang harus dikuasai oleh atlet atau pemain (Herdinata, 2015). Berdasarkan hal tersebut, dapat diketahui bahwa selain dituntut untuk memiliki kemampuan fisik dan teknik yang baik, seorang pemain anggar juga harus memiliki mental dan konsentrasi yang baik pula agar dapat melakukan serangan dengan cepat dan menusuk lawan dengan tepat (Rasyono \& Decheline, 2019).

Penelitian sebelumnya menyebutkan bahwa sebagian besar faktor yang menyebabkan rendahnya tingkat akurasi tusukan dalam olahraga anggar berkaitan dengan faktor mental, yaitu kurang fokus dan terburu-buru. Dalam studi yang dilakukan oleh Herdinata (2015) ditemukan fakta bahwa masih banyak atlet yang terlihat gugup dan tergesa-gesa dalam melakukan serangan. Banyak faktor yang menyebabkan hal tersebut terjadi, salah satunya karena tingkat perhatian dan fokus atlet mudah terganggu oleh distraksi atau rangsangan yang muncul secara bersamaan, baik dari faktor lingkungan, penonton maupun dari atlet itu sendiri (Septiyanto \& Suharjana, 2016). Semua gangguan tersebut menyebabkan atlet tidak dapat berkonsentrasi secara penuh pada bidang sasaran, yang pada akhirnya menyebabkan tusukan menjadi meleset. Hal ini sungguh disayangkan, mengingat akurasi atau ketepatan tusukan merupakan salah satu poin penting yang berkontribusi besar dalam mencetak angka (Ma’arif, 2015).

Berbagai macam metode latihan telah dikembangkan untuk meningkatkan ketepatan tusukan, seperti melalui latihan serangan (lunge) atau latihan kelincahan yang dilakukan secara berulang-ulang. Namun 
sampai sejauh ini, metode latihan yang diterapkan lebih banyak berupa latihan fisik yang bertujuan untuk meningkatkan skill dan kemampuan atlet saja, dan hanya sedikit yang memberikan metode berupa latihan mental (Pulungan \& Dimyati, 2019). Padahal, latihan mental merupakan hal yang penting dalam upaya mengelola perhatian dan konsentrasi atlet atau pemain untuk diarahkan pada teknik menyerang dan menusuk dengan tujuan dapat meningkatkan persentase keberhasilan dan akurasi tusukan (Septiyanto \& Suharjana, 2016). Beberapa contoh latihan mental yang dapat dilakukan antara lain self-hypnosis, self-talk, visualisasi, relaksasi, konsentrasi dan imagery (Wibowo \& Rahayu, 2016). Diantara berbagai metode tersebut, latihan imagery atau imagery training merupakan salah satu metode latihan yang banyak digunakan dalam berbagai cabang olahraga, sebab latihan ini memiliki banyak dampak positif terhadap peningkatan performa atlet, mulai dari meningkatkan kecepatan dalam sprint (Iftikhar, Mallett, \& Javed, 2018) hingga memperbaiki akurasi servis bola voli (Septiyanto \& Suharjana, 2016) dan tenis (Lindsay, Spittle, \& Larkin, 2019). Selain latihan imagery, latihan konsentrasi juga dapat dilakukan untuk meningkatkan fokus atlet. Beberapa jenis latihan konsentrasi yang dapat dilakukan antara lain latihan untuk mengubah perhatian (learning to shift attention), latihan untuk mempertahankan fokus (learning to maintain focus), latihan mencari kunci yang relevan (searching for relevant cues), atau melalui permainan (rehearsing game ocncentration) (Nusufi, 2016). Setiap atlet harus memiliki keterampilan konsentrasi yang baik agar dapat memberikan performa terbaiknya selama berlatih atau bertanding. Oleh sebab itu, latihan konsentrasi menjadi salah satu latihan mental yang perlu dilakukan oleh atlet atau pemain.

Berdasarkan permasalahan di atas, dapat disimpulkan bahwa latihan mental memiliki banyak manfaat untuk meningkatkan performa atlet atau pemain anggar, khususnya dalam meningkatkan keterampilan menyerang dan menusuk. Namun, sampai saat ini belum banyak penelitian yang mengangkat topik mengenai latihan imagery dan latihan konsentrasi. Oleh sebab itu, dilakukanlah penelitian ini dengan tujuan untuk mengetahui pengaruh latihan imagery dan konsentrasi terhadap ketepatan tusukan yang dilakukan oleh siswa pemain anggar.

\section{Metode Penelitian}

Penelitian ini merupakan penelitian eksperimen semu yang menggunakan pretest-posttest control group design. Penelitian ini melibatkan 15 orang siswa yang mengikuti ekstrakulikuler anggar di SMA Muhammadiyah 3 Surabaya. Siswa-siswa tersebut kemudian dibagi menjadi tiga kelompok, yaitu kelompok kontrol (C), kelompok yang diberi latihan imagery (IM), dan kelompok yang diberi latihan konsentrasi (KT). Pembagian kelompok dilakukan dengan teknik matched subject ordinal pairing, yaitu suatu cara pengelompokan sampel dengan cara menyusun subyek ke dalam suatu urutan perankingan kemudian anggota sampel untuk masing-masing kelompok diambil dengan mengikuti pola huruf "S" (Gambar 1) (Hadi, 2004). Tujuan penggunaan teknik ini adalah untuk menyamakan kualitas anggota atau sampel dari masing-masing kelompok.

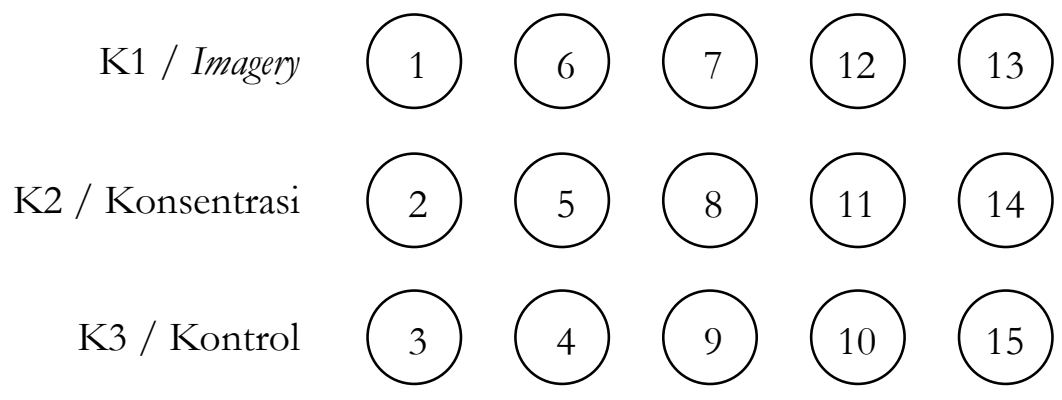

Gambar 1. Skema Pembagian Kelompok Menggunakan Matched Subject Ordinal Pairing 
Latihan imagery dilakukan dengan mendemonstrasikan gerakan tertentu kepada responden, lalu responden diminta untuk membayangkan gerakan-gerakan tersebut dengan fokus dan seksama. Selanjutnya, responden diminta memperagakan gerakan tersebut hingga benar. Sedangkan untuk latihan konsentrasi dilakukan menggunakan grid concentration test. Tes ini dilakukan dengan memberikan instruksi kepada responden untuk mencari kunci-kunci yang relevan dari beberapa blok angka mulai dari 00 hingga 99. Responden diminta untuk memberikan tanda terhadap angka-angka tersebut secara berurutan dalam waktu 1-2 menit hingga responden bisa memiliki konsentrasi yang baik. Setelah enam minggu diberikan latihan, ketepatan tusukan responden kemudian diukur menggunakan kuhadja atau fencing skill test. Tusukan dinyatakan akurat apabila ujung senjata menyentuh lingkaran pada bidang sasaran.

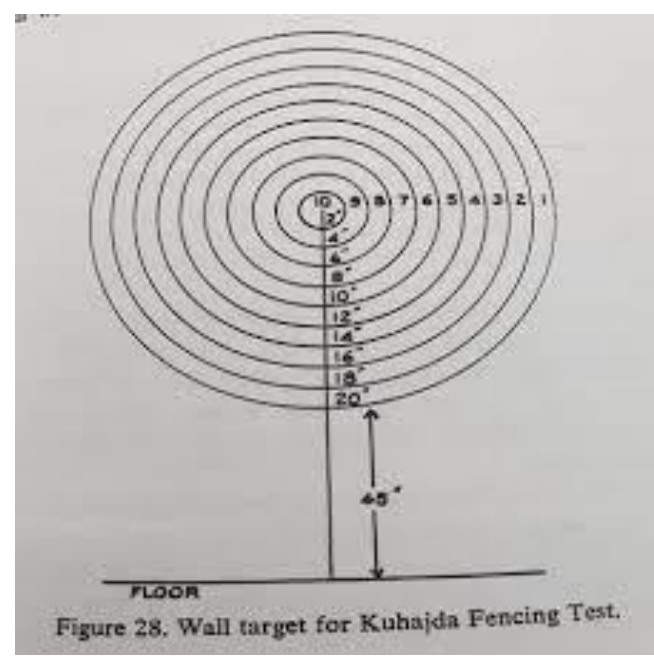

Gambar 2. Wall target atau bidang sasaran pada fencing skill test (Afriadi, 2019)

Data yang terkumpul kemudian dianalisis menggunakan statistik deskriptif dan inferensial. Statistik deskriptif dilakukan dengan menyajikan rerata skor dan simpangan bakunya (mean \pm SD), sedangkan statistik inferensial dilakukan dengan uji t berpasangan (paired t-test), Wilcoxon signed rank test, dan Anova one way, dengan taraf kepercayaan sebesar $95 \%$.

\section{Hasil}

Penelitian ini melibatkan 15 siswa yang mengikuti ekstrakulikuler anggar di SMA Muhammadiyah 3 Surabaya, dengan tujuan untuk mengetahui pengaruh latihan imagery dan konsentrasi terhadap ketepatan tusukan. Hasil analisis deskriptif dirangkum dalam Tabel 1 sebagai berikut.

Tabel 1. Hasil Analisis Deskriptif Terhadap Ketepatan Tusukan

\begin{tabular}{lccccccc}
\hline \multirow{2}{*}{ Kelompok } & \multirow{2}{*}{ n } & \multicolumn{2}{c}{ Pre } & \multicolumn{2}{c}{ Post } & \multicolumn{2}{c}{ Ketepatan Tusukan* } \\
\cline { 3 - 7 } & & Min & Maks & Min & Maks & Pre & Post \\
\hline Imagery (IM) & 5 & 7.00 & 9.00 & 8.00 & 10.00 & $8.00 \pm 0.71$ & $9.00 \pm 0.71$ \\
Konsentrasi (KT) & 5 & 7.00 & 9.00 & 9.00 & 10.00 & $8.20 \pm 0.84$ & $9.80 \pm 0.45$ \\
Kontrol (C) & 5 & 7.00 & 10.00 & 7.00 & 10.00 & $8.20 \pm 1.30$ & $8.40 \pm 1.14$ \\
\hline
\end{tabular}

*disajikan dalam mean $\pm S D$

Hasil analisis deskriptif yang telah dilakukan pada tiga kelompok menunjukkan adanya perbedaan rerata ketepatan tusukan sebelum dan sesudah diberi perlakuan berupa latihan imagery dan konsentrasi. Pada kelompok yang diberi latihan imagery, terjadi peningkatan rerata skor ketepatan tusukan dari 8.00 \pm 0.71 menjadi $9.00 \pm 0.71$. Hal serupa juga dijumpai pada kelompok responden yang diberi latihan konsentrasi, dimana rerata skor ketepatan tusukan mengalami kenaikan dari $8.20 \pm 0.84$ menjadi 9.80 
\pm 0.45. Sedangkan skor ketepatan tusukan pada kelompok kontrol berubah dari $8.20 \pm 1.30$ menjadi $8.40 \pm 1.14$

Tabel 2. Hasil Uji Normalitas

\begin{tabular}{lcccc}
\hline \multicolumn{1}{c}{ Kelompok } & n & \multicolumn{2}{c}{ p-value } & Keterangan \\
\hline Imagery (IM) & 5 & 0.759 & 0.759 & Normal \\
Konsentrasi (KT) & 5 & 0.953 & 0.214 & Normal \\
Kontrol (C) & 5 & 0.967 & 0.941 & Normal \\
\hline
\end{tabular}

Hasil uji normalitas pada Tabel 2 menunjukkan bahwa skor ketepatan tusukan pada kelompok perlakuan (IM) dan (KT) memiliki distribusi yang normal baik sebelum dan sesudah diberi perlakuan ( $p>0.05)$. Sedangkan skor ketepatan tusukan pada kelompok kontrol tidak berdistribusi normal. Dengan begitu, analisis lanjutan untuk mengetahui pengaruh latihan imagery dan konsentrasi terhadap ketepatan tusukan dapat dilakukan menggunakan paired t-test dan Wilcoxon signed rank test (Tabel 3).

\section{Tabel 3. Hasil Uji Perbedaan terhadap Skor Ketepatan Tusukan Sebelum dan Sesudah Perlakuan}

\begin{tabular}{|c|c|c|c|c|c|}
\hline \multirow{2}{*}{ Kelompok } & \multirow{2}{*}{$\mathbf{n}$} & \multicolumn{2}{|c|}{ Ketepatan Tusukan } & \multirow[b]{2}{*}{$\mathbf{t}$} & \multirow{2}{*}{$p$-value } \\
\hline & & Pre & Post & & \\
\hline Imagery (IM) & 5 & $7.90 \pm 2.19$ & $9.00 \pm 0.70$ & 3.16 & $0.034 *$ \\
\hline Konsentrasi (KT) & 5 & $8.12 \pm 0.75$ & $9.80 \pm 0.44$ & 4.00 & $0.016^{*}$ \\
\hline Kontrol & 5 & $8.20 \pm 1.30$ & $8.40 \pm 1.14$ & 0.54 & 0.621 \\
\hline
\end{tabular}

*signifikan pada $p=0.05$

Hasil uji beda menggunakan paired t-test diketahui bahwa nilai signifikansi pada kelompok imagery (IM), konsentrasi (KT), dan kontrol secara berturut-turut sebesar sebesar 0.034, 0.016, dan 0.621. Hasil ini menunjukkan bahwa rerata skor ketepatan tusukan pada kedua kelompok sebelum dan sesudah perlakuan memang berbeda secara statistik, sedangkan pada kelompok kontrol tidak ditemukan perbedaan yang signifikan. Berdasarkan hasil ini, dapat disimpulkan bahwa perlakuan yang diberikan kepada kelompok sampel berupa latihan imagery dan konsentrasi memberikan pengaruh yang signifikan terhadap ketepatan tusukan.

Tabel 4. Perbedaan Pengaruh Jenis Latihan terhadap Ketepatan Tusukan

\begin{tabular}{llcc}
\hline & Kelompok & $\boldsymbol{\Delta}$ Mean & p-value \\
\hline Imagery (IM) & Konsentrasi (KT) & -0.800 & $0.002^{*}$ \\
& Kontrol (C) & 0.000 & $0.001^{*}$ \\
Konsentrasi (KT) & Imagery (IM) & 0.800 & $0.002^{*}$ \\
& Kontrol (C) & 0.800 & $0.000^{*}$ \\
Kontrol (C) & Imagery (IM) & 0.000 & $0.001^{*}$ \\
& Konsentrasi (KT) & -0.800 & $0.000^{*}$ \\
\hline
\end{tabular}

*signifikan pada $p=0.05$

Berdasarkan hasil analisis menggunakan Anova one-way dapat diketahui bahwa jenis latihan yang diberikan kepada responden memberikan perbedaan yang signifikan terhadap ketepatan tusukan. Dan dari hasil analisis lanjutan menggunakan uji Tukey diketahui bahwa ketepatan tusukan dari responden yang tidak diberi latihan apapun (C) secara statistik menunjukkan beda yang signifikan dibandingkan responden yang diberi latihan imagery (IM) atau konsentrasi (KT), dengan nilai signifikansi secara berturut-turut sebesar 0.001 dan 0.000 . 


\section{Pembahasan}

Penelitian ini bertujuan untuk mengetahui pengaruh metode latihan imagery dan konsentrasi terhadap ketepatan tusukan pemain anggar. Metode latihan yang diberikan merupakan bentuk latihan mental, sebab faktor psikologis memegang peran penting dalam meningkatkan performa seorang atlet, sebagaimana faktor fisik dan teknik juga turut meningkatkan keberhasilan atlet dalam suatu pertandingan (Sohrabi, Taheri, Hajatmand Ghalehroudkhani, \& Ghodusi Tabar, 2014).

Berdasarkan hasil penelitian, diketahui bahwa metode latihan imagery dan konsentrasi yang diberikan terbukti lebih efektif dalam meningkatkan skor ketepatan tusukan dibandingkan dengan responden yang tidak mendapatkan perlakuan apapun $(\mathrm{p}<0.05)$ (Tabel 3). Metode latihan imagery dan konsentrasi yang diberikan dapat meningkatkan skor ketepatan tusukan. Temuan ini serupa dengan hasil penelitian Fitria (2018) yang menyebutkan bahwa latihan imagery memberikan pengaruh signifikan terhadap peningkatan akurasi atau ketepatan tusukan dalam olahraga anggar $(\mathrm{p}=0.012)$. Ada beberapa mekanisme yang dapat menjelaskan hal ini, salah satunya yaitu melalui serangkaian proses yang melibatkan sekresi hormon endorfin. Latihan imagery dapat menghasilkan respon psikologis lebih tinggi, yang mana respon psikologis tersebut dapat merangsang sekresi hormon endorfin lebih banyak sehingga memberikan efek tenang dan rasa nyaman kepada atlet pada saat berlatih atau bertanding (Septiyanto \& Suharjana, 2016). Efek relaksasi ini lah yang membantu atlet atau pemain untuk bisa berkonsentrasi lebih baik. Dalam studi lain disebutkan bahwa latihan imagery dapat membantu atlet mengatasi kecemasan yang muncul pada saat berlatih atau bertanding serta meningkatkan kesiapan dan kepercayaan diri atlet (Weinberg, 2008).

Selain itu, dalam penelitian lain disebutkan bahwa latihan imagery yang dilakukan secara berulang-ulang dapat merangsang aktivasi beberapa bagian otak yang biasanya akan aktif ketika pemain melakukan gerakan yang sesungguhnya. Dengan kata lain, pada saat pemain melakukan latihan imagery, aktivitas yang dilakukan oleh otak pada saat itu akan sama seperti aktivitas otak pada saat pemain melakukan actual movement atau gerakan secara langsung (Mizuguchi, Nakata, Uchida, \& Kanosue, 2012). Apabila latihan ini dilakukan secara berulang, maka otak akan terotomisasi untuk merekam gerakan-gerakan yang dibayangkan sebagai memori jangka pendek. Oleh sebab itu, ketika gerakan tersebut dipraktikkan maka otak akan secara otomatis untuk melakukan gerakan serupa dengan lebih baik, yang pada akhirnya dapat meningkatkan performa atlet/pemain tersebut (Sohrabi et al., 2014). Otomatisasi yang dilakukan oleh otak sebagai dampak dari latihan imagery yang dilakukan secara terus menerus juga dapat mempersingkat durasi waktu dari suatu gerakan yang dilakukan, terutama untuk multiple-target armpointing task yang membutuhkan kecepatan dan akurasi spasial tinggi seperti anggar (Mizuguchi et al., 2012).

Selain dipengaruhi oleh latihan imagery, ketepatan tusukan pemain anggar juga dipengaruhi oleh latihan konsentrasi. Hal tersebut dibuktikan dalam studi ini, dimana kelompok responden yang diberi latihan konsentrasi memiliki skor ketepatan tusukan yang signifikan lebih tinggi dibanding responden yang tidak mendapat latihan apa-apa $(\mathrm{p}=0.000)$. Konsentrasi merupakan suatu keadaan dimana kesadaran seseorang tertuju pada suatu objek tertentu (Pamungkas, 2016). Sport psychologists, pelatih, dan para ahli di bidang olahraga sepakat bahwa attentional skill seperti konsentrasi merupakan faktor esensial yang turut menentukan keberhasilan dalam suatu pertandingan (Moran, 2016).

Pemain anggar harus dapat berkonsentrasi penuh dalam melakukan setiap pergerakan, mulai dari posisi sedia hingga melakukan serangan harus dilakukan dengan cepat, tepat, dan akurat agar dapat mencetak skor (Ma'arif, 2015). Seorang pemain anggar dituntut untuk dapat melakukan analisis dan memilih rangsangan visual dari lawan dengan cepat sebelum lawan melakukan gerakan (Hagemann, Schorer, Canal-Bruland, Lotz, \& Strauss, 2010; Roi \& Bianchedi, 2008). Rangsangan ini kemudian diterima oleh otak dan akan dilepaskan dalam bentuk gerakan balasan berupa menghindar atau menyerang dalam waktu yang cepat. Untuk melakukan hal ini, pemain anggar harus memiliki 
konsentrasi yang baik agar bisa memproses informasi dalam waktu yang singkat (Sorel et al., 2019). Selain itu, latihan konsentrasi juga dapat membantu pemain dalam menentukan dan mengarahkan ujung senjata tepat pada titik bidang tusukan lawannya. Berdasarkan penjelasan tersebut, maka konsentrasi memegang peran besar dalam menentukan performa seorang atlet sebab konsentrasi dapat membantu atlet dalam melakukan eksekusi teknik (Septiyanto \& Suharjana, 2016). Maka menjadi hal yang tidak bisa dipungkiri lagi bila pemain yang memiliki konsentasi tinggi akan memiliki peluang untuk menang lebih besar dibanding pemain yang memiliki konsentrasi rendah (Manurung \& Dimyati, 2019).

\section{Simpulan dan Rekomendasi}

Dari penelitian yang telah dilakukan, dapat disimpulkan faktor psikologis memiliki peran penting dalam meningkatkan performa pemain anggar, khususnya dalam hal akurasi atau ketepatan tusukan. Latihan imagery dan konsentrasi yang diberikan kepada responden terbukti dapat meningkatkan ketepatan tusukan. Namun, hasil dalam penelitian ini kurang bisa digeneralisasikan untuk pemain anggar secara keseluruhan karena keterbatasan jumlah sampel. Selain itu, keterbatasan lain dalam penelitian ini yaitu tidak adanya kontrol terhadap confounding variabel seperti karakteristik subyektif dari responden yang mungkin dapat mempengaruhi hasil penelitian, seperti usia, lama bermain anggar, dan kondisi fisik responden. Penelitian lebih lanjut perlu dilakukan untuk mengetahui lebih lanjut perbedaan pengaruh dari jenis latihan yang diberikan.

\section{Daftar Pustaka:}

Afriadi, D. (2019). Kontribusi Kelincahan dan Fleksibilitas terbadap Hasil Serangan Teknik Lunge pada Olabraga Anggar. Universitas Pendidikan Indonesia.

Chen, T. L.-W., Wong, D. W.-C., Wang, Y., Ren, S., Yan, F., \& Zhang, M. (2017). Biomechanics of fencing sport: A scoping review. PLoS ONEPLoS ONE, 12(2). https://doi.org/10.1371/journal.pone.0171578

Fahrurozi, A. F. (2016). Hubungan Kecerdasan Emosional dengan Kemampuan Bereaksi pada Olahraga Anggar di UKM Anggar UPI. Universitas Pendidikan Indonesia.

Fitria, F. (2018). Pengaruh Latihan Imagery dan Self-Talk Terhadap Konsentrasi dan Ketepatan Tusukan Dalam Permainan Anggar. Jendela Olahraga, 3(2), 19-25. https://doi.org/10.26877/jo.v3i2.2429

Green, G. W. (2016). Distinguishing characteristic of classical fencing when compared to modern fencing (Classical Academy of Arms). Classical Academy of Arms. https://doi.org/10.13140/RG.2.2.29787.16169

Hadi, S. (2004). Metodologi Penelitian (Edisi 3). Yogyakarta: Penerbit Andi.

Hagemann, N., Schorer, J., Canal-Bruland, R., Lotz, S., \& Strauss, B. (2010). Visual perception in fencing: Do the eye movements of fencers represent their information pickup? Attention, Perception, \& Psychophysics, 72(8), 2204-2214.

Herdinata, A. F. (2015). Pengaruh Jeda/Interval pada Latiban Tusukan terhadap Ketepatan Tusukan pada Pemain Anggar IKASE Kota Semarang Tabun 2015. Universitas Negeri Semarang.

Iftikhar, M. T., Mallett, C. J., \& Javed, M. A. (2018). Imagery improves reaction time in elite srinters. 6th International Congress on Sport Sciences Research and Technology Support, 27-33. https://doi.org/10.5220/0006898300270033

Kamaruddin, I. (2011). Kontribusi kekuatan pegangan, keseimbangan, dan daya ledak tungkai iterhadap ketepatan tusukan dalam permainan anggar senjata degen. Jumal ILARA, 11(1), 1021.

Kontochristopoulos, N., \& Tsolakis, C. (2019). Offensive and defensive efficacy among male and 
female elite foil fencers. Journal of Human Sport and Exercise, 15(2), 1-9. https://doi.org/10.14198/jhse.2020.152.05

Kurniawan, F. (2010). Mengenal Cabang Olabraga Klasik, Anggar. Yogyakarta: UNY Press.

Lindsay, R., Spittle, M., \& Larkin, P. (2019). The effect of mental imagery on skill performance in sport: A systematic review. Journal of Science and Medicine in Sport, 22(S92). https://doi.org/10.1016/j.jsams.2019.08.111

Ma'arif, D. S. (2015). Kontribusi Power Lengan dan Power Tungkai Terhadap Hasil Serangan Langsung dalam Cabang Olahraga Anggar Jenis Senjata Degen. Universitas Pendidikan Indonesia.

Manurung, O. V., \& Dimyati. (2019). Influence of Training Method and Concentration to the Accuracy of Short Service Backhand in Badminton. Advances in Social Science, Education and Humanities Research, 278(YISHPESS 2018), 464-467. https://doi.org/10.2991/yishpess-cois18.2018.117

Mizuguchi, N., Nakata, H., Uchida, Y., \& Kanosue, K. (2012). Motor imagery and sport performance. The Journal of Physical Fitness and Sports Medicine, 1(1), 103-111. https://doi.org/10.7600/jpfsm.1.103

Moran, A. (2016). Attention and concentration training in sport. The Curated Reference Collection in Neuroscience and Biobehavioral Psychology, (October 2015), 209-214. https://doi.org/10.1016/B9780-12-809324-5.05476-6

Nusufi, M. (2016). Melatih Konsentrasi dalam Olahraga. Jurnal Ilmu Keolahragaan, 15(2). https://doi.org/10.24114/jik.v15i2.6139

Pamungkas, A. D. (2016). Hubungan antara Tingkat Konsentrasi terbadap Keterampilan Bermain Sepakbola pada Siswa Peserta Ekstrakulikuler Sepakbola SMPN 1 Ngaglik. Universitas Negeri Yogyakarta.

Pulungan, K. A., \& Dimyati. (2019). Karakteristik Keterampilan Psikologis Pemain Bolavoli Indonesia Ditinjau Berdasarkan Gender dan Posisi. Jurnal SPORTIF: Jurnal Penelitian Pembelajaran, 5(1), 279_ 295. https://doi.org/10.29407/js_unpgri.v5i2.13178

Rasyono, R., \& Decheline, G. (2019). Pengaruh Variasi Latihan Serangan Terhadap Ketepatan Tusukan Atlet Anggar Provinsi Jambi. Altius: Jurnal Ilmu Olahraga Dan Kesehatan, 8(2), 28-34. https://doi.org/10.36706/altius.v8i2.8895

Rimasa, D., \& Sartono, H. (2020). Kontribusi Kelincahan dan Keseimbangan terhadap Hasil Serangan Teknik Ballestra pada Olahraga Anggar Jenis Senjata Sabel. Jurnal Kepelatihan Olahraga, 12(1), 39_ 44. https://doi.org/10.17509/jko-upi.v12i1.24012

Roi, G. S., \& Bianchedi, D. (2008). The Science of Fencing: Implications for Performance and Injury Prevention. Sports Medicine, 38(6), 465-481.

Septiyanto, A., \& Suharjana, S. (2016). Pengaruh Metode Latihan Imagery dan Konsentrasi Terhadap Ketepatan Floating Service Atlet Bola Voli DIY. Jurnal Cakrawala Pendidikan, 35(3), 412-420. https://doi.org/10.21831/cp.v35i3.8249

Sohrabi, M., Taheri, H., Hajatmand Ghalehroudkhani, H., \& Ghodusi Tabar, M. (2014). The Effect of Mental Imagery Focus of Attention on Performance and Learning of Children Dart Throwing Skill. International Journal of Sport Studies, 4(2), 161-167.

Sorel, A., Plantard, P., Bideau, N., \& Pontonnier, C. (2019). Studying fencing lunge accuracy and response time in uncertain conditions with an innovative simulator. PLoS ONE, 14(7). https://doi.org/10.1371/journal.pone.0218959

Weinberg, R. (2008). Does Imagery Work? Effects on Performance and Mental Skills. Journal of Imagery Research in Sport and Physical Activity, 3(1). https://doi.org/10.2202/1932-0191.1025 
Wibowo, S. A. P., \& Rahayu, N. I. (2016). Pengaruh Latihan Mental Imagery Terhadap Hasil Tembakan Atlet Menembak Rifle Jawa Barat. Jurnal Terapan Ilmu Keolabragaan, 1(2), 23. https://doi.org/10.17509/jtikor.v1i2.2776

Widowati, A., \& Decheline, G. (2020). Modifikasi Senjata Anggar Untuk Meningkatkan Kekuatan Otot Lengan Pada Atlet Anggar Pemula. Physical Activity Journal, 2(1), 109-124. https://doi.org/10.20884/1.paju.2020.2.1.3331

Yanto, A. (2013). Perbandingan antara Tangkisan Dua dengan Tangkisan Delapan terbadap Ketepatan Tusukan Riposte pada Atlet Anggar Jenis Senjata Degen. Universitas Pendidikan Indonesia. 